This item was submitted to Loughborough's Research Repository by the author.

Items in Figshare are protected by copyright, with all rights reserved, unless otherwise indicated.

\title{
Higher education lectures: from passive to active learning via imagery?
}

\section{PLEASE CITE THE PUBLISHED VERSION}

https://doi.org/10.1177/1469787417731198

\section{PUBLISHER}

(c) The Author. Published by SAGE Publications.

\section{VERSION}

AM (Accepted Manuscript)

\section{PUBLISHER STATEMENT}

This work is made available according to the conditions of the Creative Commons Attribution-NonCommercialNoDerivatives 4.0 International (CC BY-NC-ND 4.0) licence. Full details of this licence are available at: https://creativecommons.org/licenses/by-nc-nd/4.0/

\section{LICENCE}

CC BY-NC-ND 4.0

\section{REPOSITORY RECORD}

Roberts, David. 2017. "Higher Education Lectures: From Passive to Active Learning via Imagery?". Loughborough University. https://hdl.handle.net/2134/23362. 
Higher education lectures: From passive to active learning via imagery?

David Roberts

\title{
Contact/biographical details of author(s)
}

David Roberts, SBE, Loughborough University, Epinal Way, Loughborough LE11 3TU, UK. Tel: 07964 885660. Email d.roberts@lboro.ac.uk

David Roberts is Senior Lecturer in Peace and Conflict Studies. His research areas are divided between postconflict peacebuilding in places like Cambodia and Sierra Leone, and ways to transform the large group lecture experience for students and teachers alike.

\begin{abstract}
An important contemporary challenge to the large group lecture in higher education is that it encourages passive learning which is claimed to be out of sync with intellectual expectations and social needs. Attempts to change this practice have salvaged some aspects of the higher education experience for students, but they have not transformed the learning environment that is the most usual one, that is, one characterised by lectures, into an arena of active learning. This article tests recent multimedia learning propositions which claim that using certain images dislocates pedagogically harmful excesses of text, reducing cognitive overloading and exploiting under-used visual processing capacities. The experiments yielded unpredicted results which indicate that the use of certain images can also prompt students to become active co-producers of knowledge. This is not about visual aids, where images are a side-bar to a traditional lecture. This is about images as the medium through which active learning is energised. Marshall McLuhan famously remarked that 'the medium is the message'. But for this article, the message is the medium.
\end{abstract}

Keywords

Active Learning; Images; PowerPoint; Multimedia Learning; Lectures

Active and Inquiry-guided learning (IGL) 
Higher Education in the global economy takes front and centre place with western governments all over the world. Universities face mounting pressure to expand participation, conform to transparency demands and match provision and relevance to dynamic workplace needs (Lawson, et al., 2015). Change is the norm in higher education, yet one thing remains constant: the large-group lecture. As a cost-effective mechanism for processing student bodies, it has no peer, a situation that will likely remain the norm as state revenue decreases and student numbers increase. Yet the idea of the wholesale processing of large numbers of students in digital lecture theatres as a viable pedagogy, whilst remaining an elephant in the room, stubbornly persists despite a range of challenges. Such challenges include concerns that too many student learning needs are submerged to one pedagogy; that two-hour lectures cannot match changing attention spans, and that the idea of a knowledge being imprinted onto passive minds in a dimly-lit room on a campus for two hours at a time is at odds with the kind of conditions needed to engage better student learning (Wolff, et al., 2015). Active- and Inquiry-Guided Learning practices (IGL) have been successfully applied to transform engagement in smaller teaching environments and for small sections of large group lectures. The challenge remains, however, in how to achieve similar results as a matter of course for a lecture's entirety, for whole modules cross the entire academic year in many disciplines, as a constant norm in large group lectures.

Anthony maintains that active learning involves knowledge construction in contrast with knowledge absorption; builds on existing knowledge; and is known to be occurring to the learner (1996). Prince similarly argues that active learning is present when learning activities mean that a student is active in the process of learning and consider what they are presented with critically, as opposed to just replicating and regurgitating academic stock (2004). These processes crystalize in Dewey's requirement for a problematic situation to stimulate a search for a solution (Savery, 2006). Torp and Sage similarly identify problemsolving as an essence of active learning (2002), as does Savery (2006). Michael (2006) argues that active learning similarly makes demands upon students to think about what they are being asked to learn, rather than just learning it, by means of being involved in the production of knowledge as opposed to being its consumers, a view supported by many (Zepke, 2013; Zepke and Leach 2010; Baeten et al, 2010). This necessarily involves them in processes like data collection and problem-solving, both of which require independent thought. These key elements and more are present for Winterbottom (2016), who argues that active learners learn by addressing and posing scientific questions, analysing evidence, connecting such evidence to pre-existing theoretical knowledge, drawing conclusions, and reflecting upon their findings. Learners replace or adapt their existing knowledge and understanding (based on their prior knowledge) with deeper and more skilled levels of understanding (Hmelo-Silver, 2004; Stes et al, 2012; von Stumm and Furnham, 2012; Ellis 2016)) 
The centrality of a problem to be resolved is clear. But problems are not the only means to stimulate active learning. Inquiry-guided learning, as a genre of active learning, represents what Baxi calls a 'discursive insurrection' (1998, p. 129), challenging what we do. Levy (2012) argues that successful inquiry-guided learning is characterised by rigorous and thoughtful questions that demand students engage in a process whereby they are appropriately guided to provide answers, as opposed to being hand-fed answers. For Edelson, inquiryguided learning requires that learners are motivated to be autonomous agents of discovery who can identify new knowledge, use it to build on their existing knowledge structures, and the use that to solve problems (1999). Savery finds little difference between Problem-Based Learning (PBL) and inquiry-guided learning; both converge around the notion that the problem, or inquiry, represents the stimulant for activity to be present. An essence of both approaches is the presentation and addressing of a problem; there is no fixed notion of what the problem looks like but it must stimulate a response (Bradfield, et al., 2015). Levy (2012) offers a definition which stands as the starting point for this discussion. She writes that inquiry-guided learning can be understood as a 'cluster of related instructional approaches in which student inquiry or research drives the student experience of learning and participation in knowledge building' (2012, p. 18). Levy embellishes this and offers examples of inquiry-guided learning in the form of real world problems, complex cases and visual stimuli (2012, p. 17).

Little emphasis is given to the 'visual resources' to which Levy (2012) refers, however. It is this notion, of the potential of visual stimulation to prompt active learning, that intersects with the challenge of transforming the dominance of didactic lecturing in higher education spaces noted by scholars such as Prosser and Trigwell (2014). This junction stands at a crossroads, to extend the metaphor. Humans have entered the most visual epoch in human history, and this and near future generations of university students have been exposed to visual learning for most of their lives. Prensky's (2001) reduction of the world into those who grew up in the digital era as being technologically competent compared to those from earlier generations who are less digitally savvy was deflated by Brumberger's more nuanced recognition that age has nothing to do with being competent in the use of technology (2011; Bailey and Ngwenyama 2010; Hargittai 2010; Palfrey and Gasser 2008). Teaching and support staff have enthusiastically embraced webcasting, podcasting, lecture capture, Twitter and more (Laurillard, 2013; Morris and Chikwa, 2014; Smith and Sodano, 2011; Guertin, 2010).

These technologies accompany the 'pictorial turn' (Felten, 2008, p. 60) explained by globalization and digitization that hosts and disseminates billions of images (Mitchell, 2002; McStay, 2013; King, 2016). Facebook alone absorbs 300 million images per day (Cuthbertson, et al., 2015, p. 158). Because of this, some propose that 'digital media are the new interface between mind and world' (Donald, 2014). Mathis (2006) argues that we are presently teaching students whose visual engagement has never been greater. To that must be added their inseparability from digital communication devices. Combined, there is a potent array of means by which education may be reconsidered. The world beyond the academy is 
increasingly visual (McStay, 2013; Brumberger, 2011; Goldfarb, 2002). Students learn through an expanding array of visual stimulants. Levy (2012) hints at the potential of bringing the visual into teaching and learning spaces, but without proposing a form in which this may happen or an intellectual rationale for so doing. This is where a different literature is useful. Multimedia learning literature (discussed in greater detail below) has much to say about the role images play in learning; but it also has much to say about the harmfully textual nature of didactic teaching. This literature does not theorize the role of images in the coproduction of active learning, but application of multimedia learning theory to large group lecture practices revealed an unanticipated reaction from students Images prompted spontaneous interrogation of their meaning on the part of learners.

\section{Multimedia Learning}

Multimedia learning is concerned with a range of issues that pertain to how we process information mentally. It builds on half a century of respected work (Ayres, 2015; Paivio, 1971; Lewis, 2016) on the interface of memory and mental processing. There are three elements of the work that are important here. The first is the idea of cognitive load (Lewis, 2016). Multimedia learning argues that we digest academic information and knowledge primarily through two channels. One 'processes verbal information such as text and audio and the other channel processes visual information such as diagrams, animations and photographs' (Beacham and Alty, 2006, p. 78; Lewis, 2016). Multimedia learning literature calls this 'dualcoding' or 'dual processing'. This dual processing structure means that people learn better from a combination of words and images than words alone (Mayer 2014; Paivio 2014). Most didactic lectures privilege text, with images as occasional and rare appendages (Gaskins, 2012; Kosslyn, 2007; Bumiller, 2010; Bergman, 2012; Gabriel, 2008; Kernbach, et al., 2015). This leaves one channel overloaded and the other underexploited.

The second relevant aspect of multimedia learning theory is that too much text (in the overloaded channel) is harmful pedagogically. The literature holds that text overload increases pressure on working memory (Clark and Lyons, 2010). Working memory can be understood as 'a cognitive operation in which some bits of information are held in a store characterized by rapid decay in memory while other bits are retrieved from long-term storage' (Siegel and Ryan, 1989, p. 973; Clark and Lyons, 2010). It's comparable to the Random Access Memory (RAM) in a computer (Lewis, 2016; Mayer and Moreno, 2003). RAM runs software that is being used in the moment and it is limited in size, compared to longer-term storage. It is why we often have trouble remembering long phone numbers but may still recall the toys of our childhoods in detail. Too much text overloads short-term memory and harms the ability to process and understand (Mayer 2014; Lewis 2016; Ayres 2015; Clark and Lyons 2010; Schrand 2008). Conducting 2 hour lectures where most slides are loaded with text overloads the ability to process this material and is pedagogically counterproductive and harmful. Schrand calls this type of delivery 'shovelware' (2008). He argues that although digital platforms (Learn, Blackboard, PowerPoint) have transformed 
higher education learning spaces, we tend to repackage the material we used before digitization and deliver it through the new platforms rather than rethink what we are delivering and how we do so using the new delivery systems. The text-heavy nature of modern digital platforms (which is undoubtedly changing, albeit slowly) often derives from text-heavy pre-digital lectures being re-potted into slides.

The third element of multimedia learning is the role of images. Images do many things, it is claimed. They draw students into them (Mayer, 2014); help to make familiar the unfamiliar (Dent-Read, et al., 1994), focus attention (Hockley and Bancroft, 2011); and allow the brain to work more efficiently as it was intended by splitting visual and textual data instead of privileging one over the other. In short, multimedia learning theory posits that the right images used in conjunction with reduced text predicts increased engagement (Mayer, 2014; Lewis, 2016).

Although multimedia learning does not offer a typology of images used in 'real world' contents, it would be useful to think about what is meant by the term 'images'. In the conduct of this research, images used can be classified as literal (or representative); metaphorical (or figurative), and paradoxical, which can straddle both. Literal images are the simplest. They manifest a visual representation of a subject and furnish a description of the unfamiliar. An example might be of an Asaro Mudman in full battle regalia. Figurative images as a second category may also be referred to as metaphorical images. A visual metaphor is an 'image... used in place of another to suggest an analogy between the two images' (Williams, 1998). We might consider an image of a diamond with blood dripping off it. Eppler proposes that visual metaphors 'support learners in connecting what they already know (the properties of the metaphor domain) with new material (the domain unto which the metaphor is being applied)'. Visual metaphors may be used to convey complex messages as opposed to serving a more illustrative purpose. An example appears in Figure 6, where a hand grenade is situated in proximity to nuclear electricity production to convey a sense of danger. A third type of image is the paradox image. A paradox is a statement that may appear to be self-contradictory but which may simultaneously communicate a truth (Eliason 1996). Paradox images may present as puzzles, creating temporary confusion generating internal attempts at reconciling meaning. An example of this might involve a lion looking at itself in a mirror and seeing the reflection of a kitten.

We now need to find more out about two inter-related issues. First, we need to consider how multimedia learning might happen in lectures attended by students who have evolved in a very visual era. It has been argued that students have been conspicuously absent from research on student engagement (Trowler, 2010) and so the research described in this article adds to this. Second, we need to ascertain whether and to what extent reducing text and introducing images into digital presentations in these settings affects student active learning. 


\section{Research methods}

\section{Participants}

Volunteers were drawn from 315 students who had been taught using multimedia learning methods on one or more modules in each academic year $(2015,2016)$ by this lecturer, the researcher, at Loughborough University in the UK and came with backgrounds in Business Studies, Economics, Marketing, Finance, Accounting, International Relations, History, Politics, Geography, Sociology, Languages and Social Work. Loughborough University is a highlyranked university of some 16,000 students, a relatively medium-sized university in UK terms. They were emailed through module lists in accordance with university ethical approval and asked if they were interested in participating in research on lecture slides. In the quantitative exercise in 2015 there were 19 students altogether and in 2016 there were 15, with a gender divide of approximately30 female/70 male. In the qualitative exercise, there were 6 students in 2015 and 7 in 2016.

\section{Study Design and procedure}

The research sought to establish the presence or absence of key characteristics of active learning from 2015-2016. The characteristics were identified from the work of Levy and others (2012). A mixed method approach was chosen. Quantitative surveys were planned to determine the presence or absence of active learning. The quantitative approach mirrors the established research methods of Chanlin (1998), McKay (1999) and Kleinman and Dwyer (1999), who conducted similar comparative research regarding moving imagery, but this experiment assesses two forms of communication only. Similar methods are used in the visual educational research of Moss and Pini (2016).

The quantitative experiment involved control and test groups exposed to a 10 -minute PowerPoint mini-lecture on global warming. The control group was exposed to text and bullet points. The test group got the same lecture delivered visually. Each group heard the same narration from the lecturer.

Since 2013 large undergraduate groups have been taught using full-slide, high-quality (minimum $800 \times 600$ pixels) images sourced through a variety of Creative Commons-framed search processes at the university in which this study was carried out. The images fill each PowerPoint slide completely, and have a few words of clear text placed unobtrusively on them which act as prompts for the lecturer and reminders for students. Approximately $80 \%$ of any single lecture is images with no more than a short line of text. The text that used to appear on slides is relocated to the 'notes' view in PowerPoint. The images are put up and then talked around, so students could listen to the auditory delivery without trying to read parallel or matching text whilst they watched, absorbed and interrogated the images for meaning based on what they already knew. Examples appear below. 
The first two images might be used to support discussion of evolution in biology, politics and critical feminist studies to name a few.

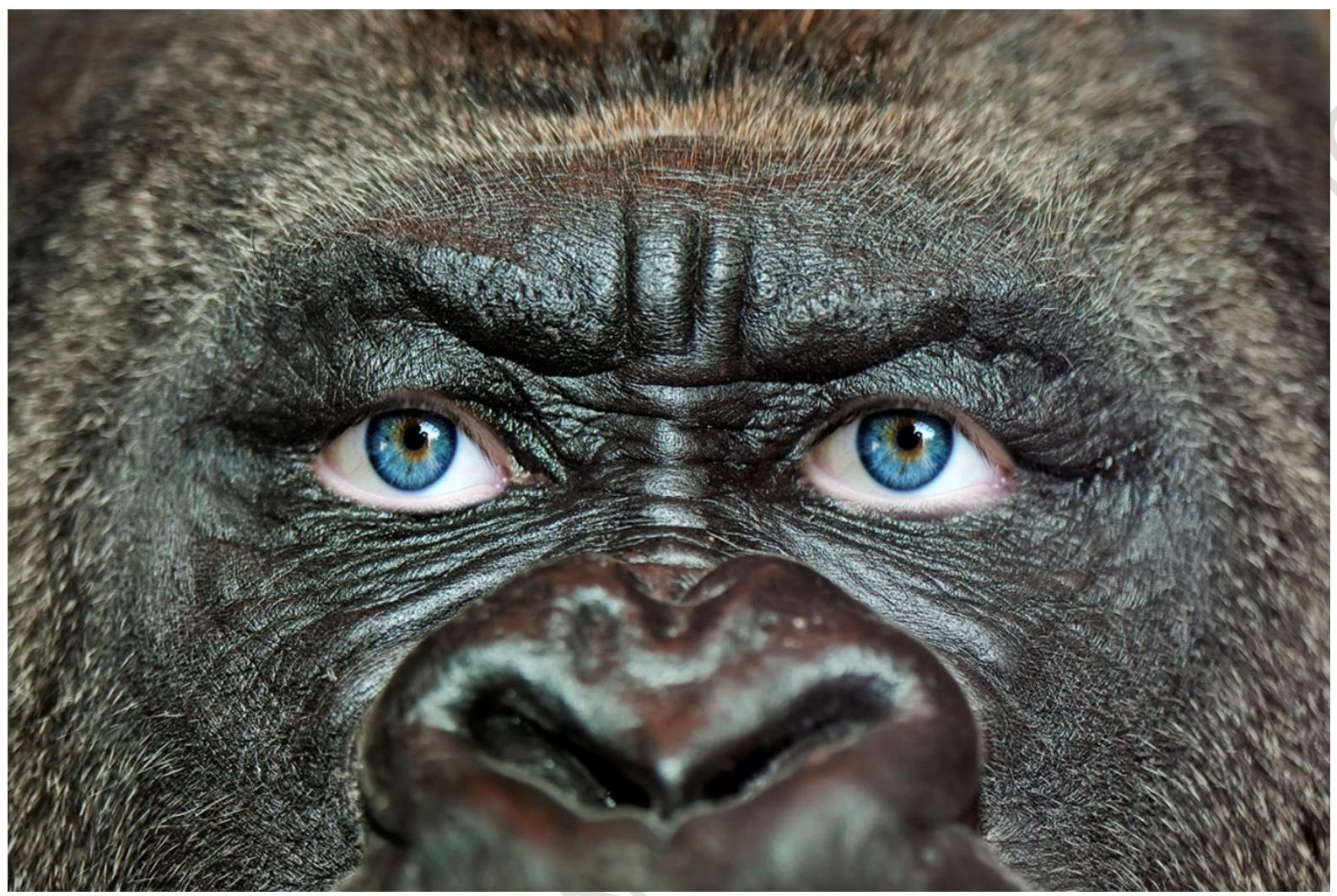

Figure 1. This image supports a discussion of the social construction of beliefs 


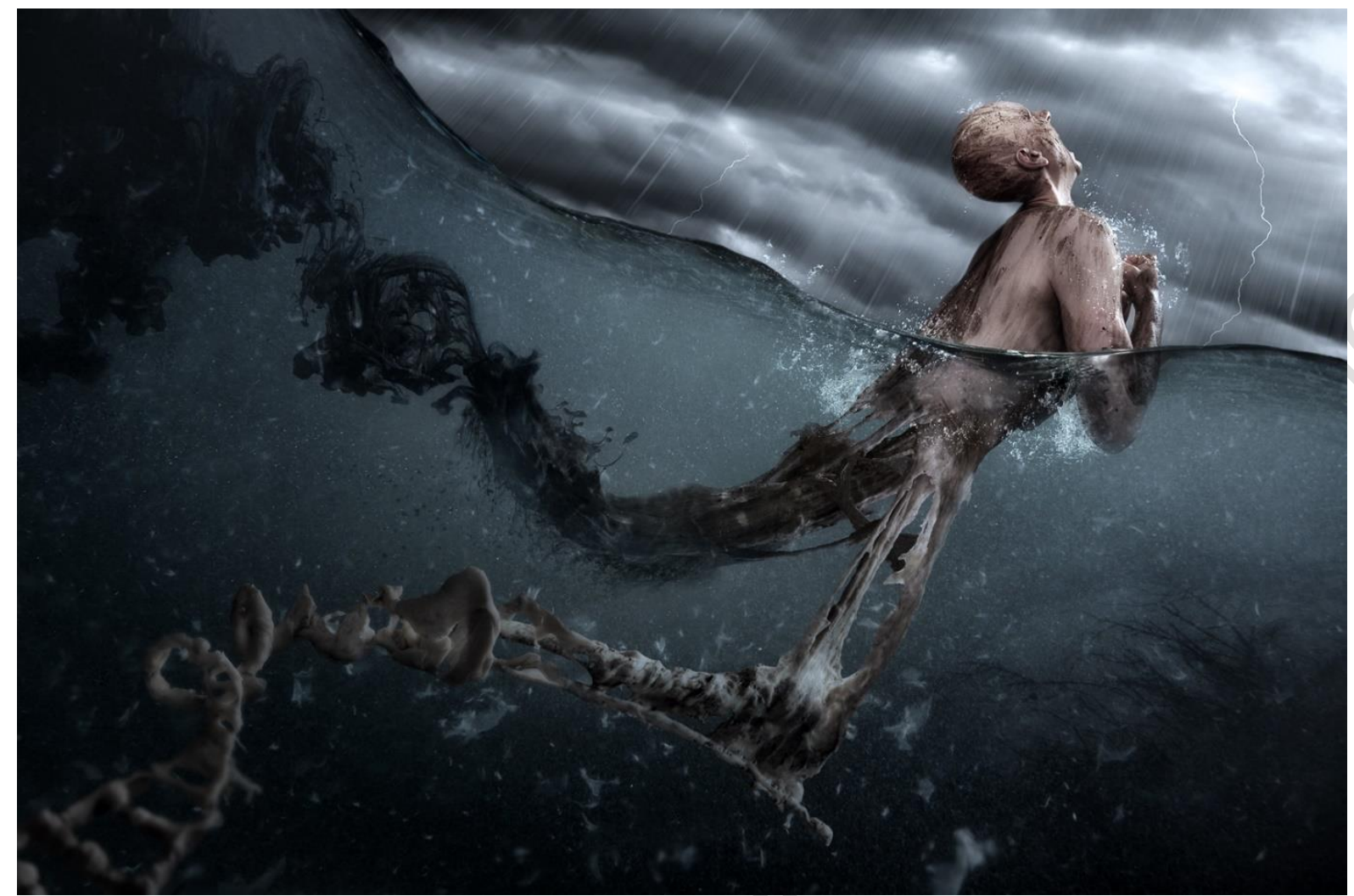

Figure 2 Evolution

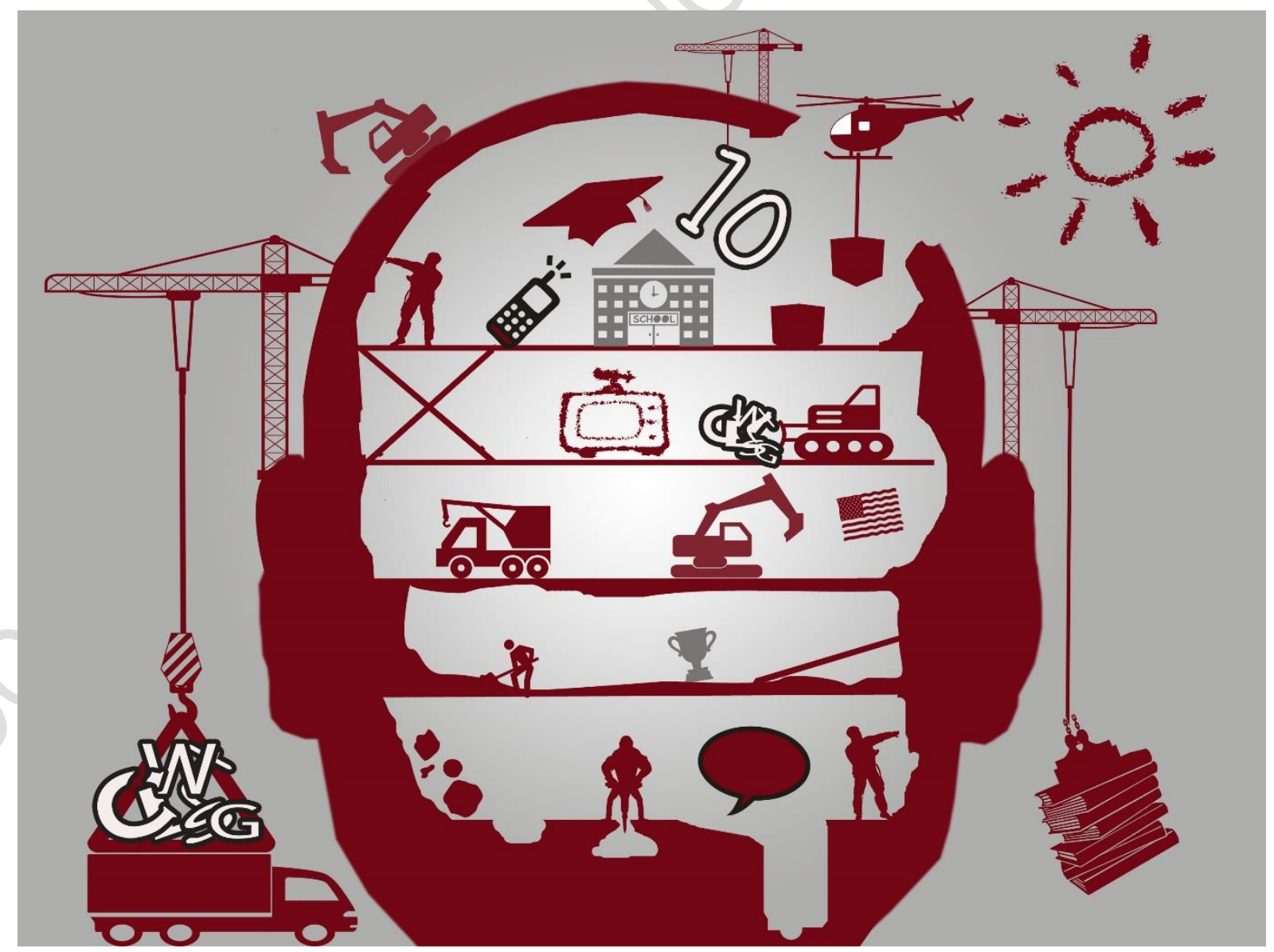

Figure 3. The social construction of the mind 


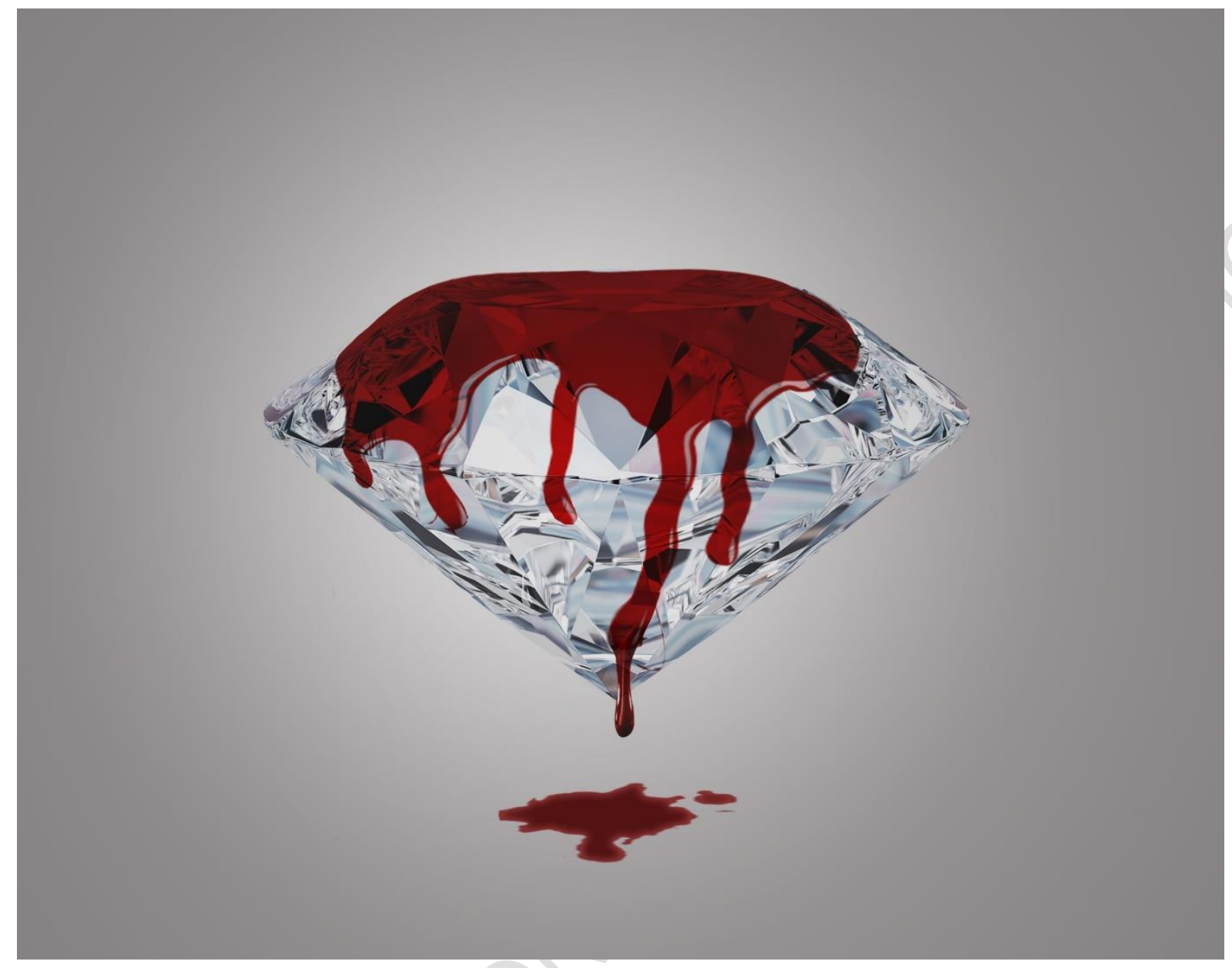

Figure 4. This image helps in the discussion of relationships between capitalism and violence 


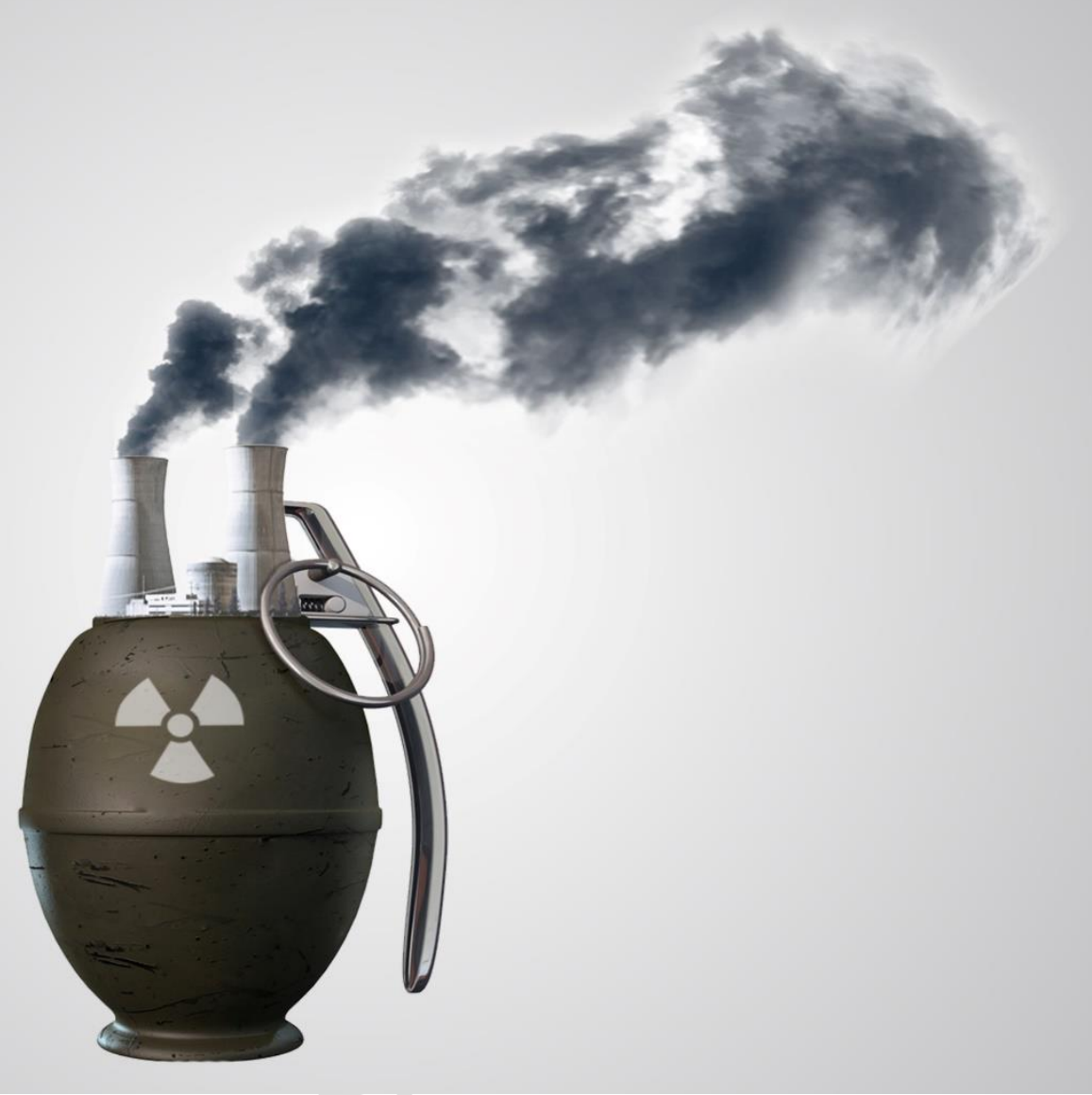

Figure 5. This image is used to suggest there may be a danger involved in commitment to nuclear energy. 


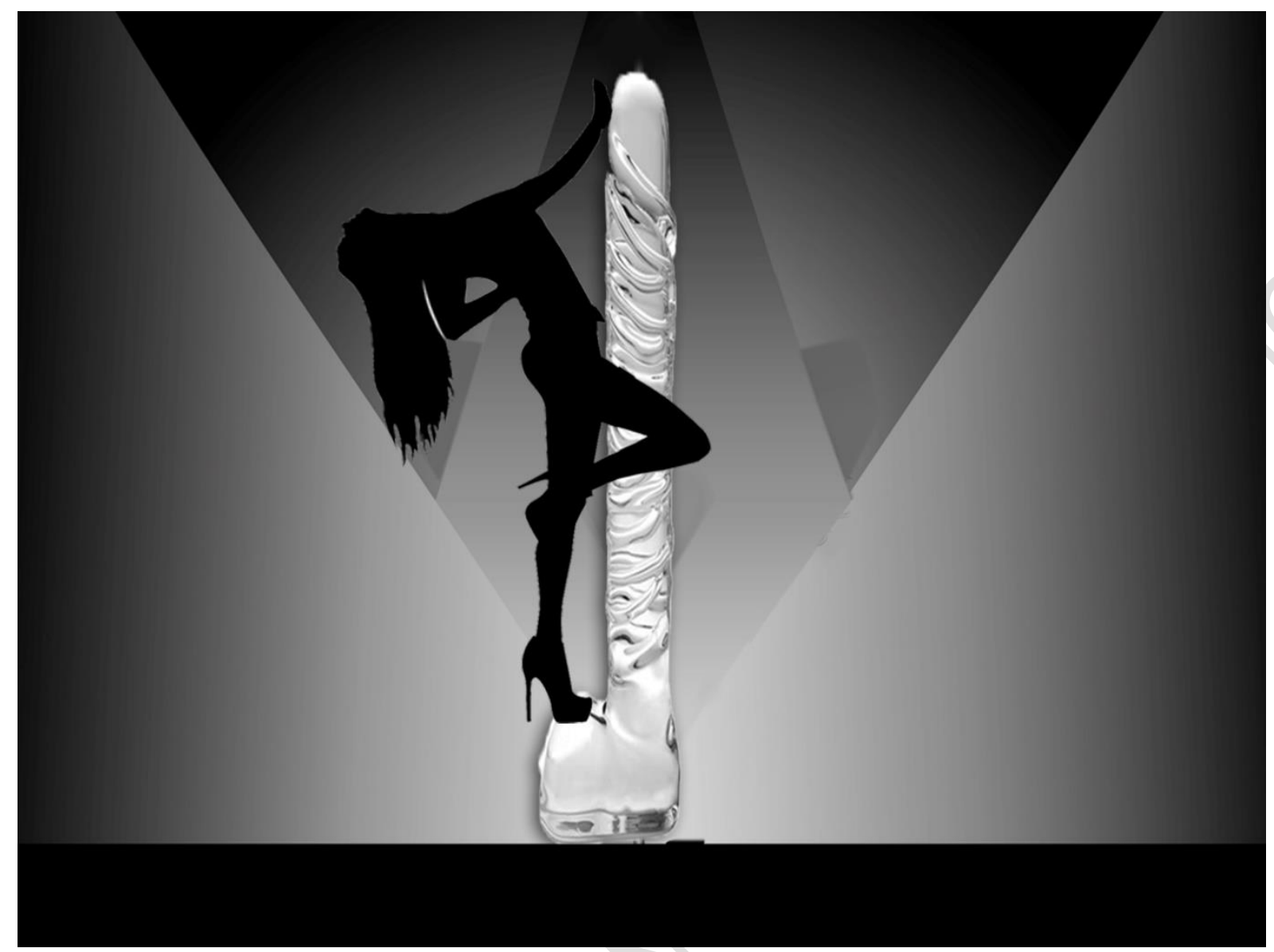

Figure 6 . This image helped the lecturer to talk about the problem of pole dancing, patriarchy and claims of Liberal feminist duplicity in maintaining oppressive hegemonic masculinity. 


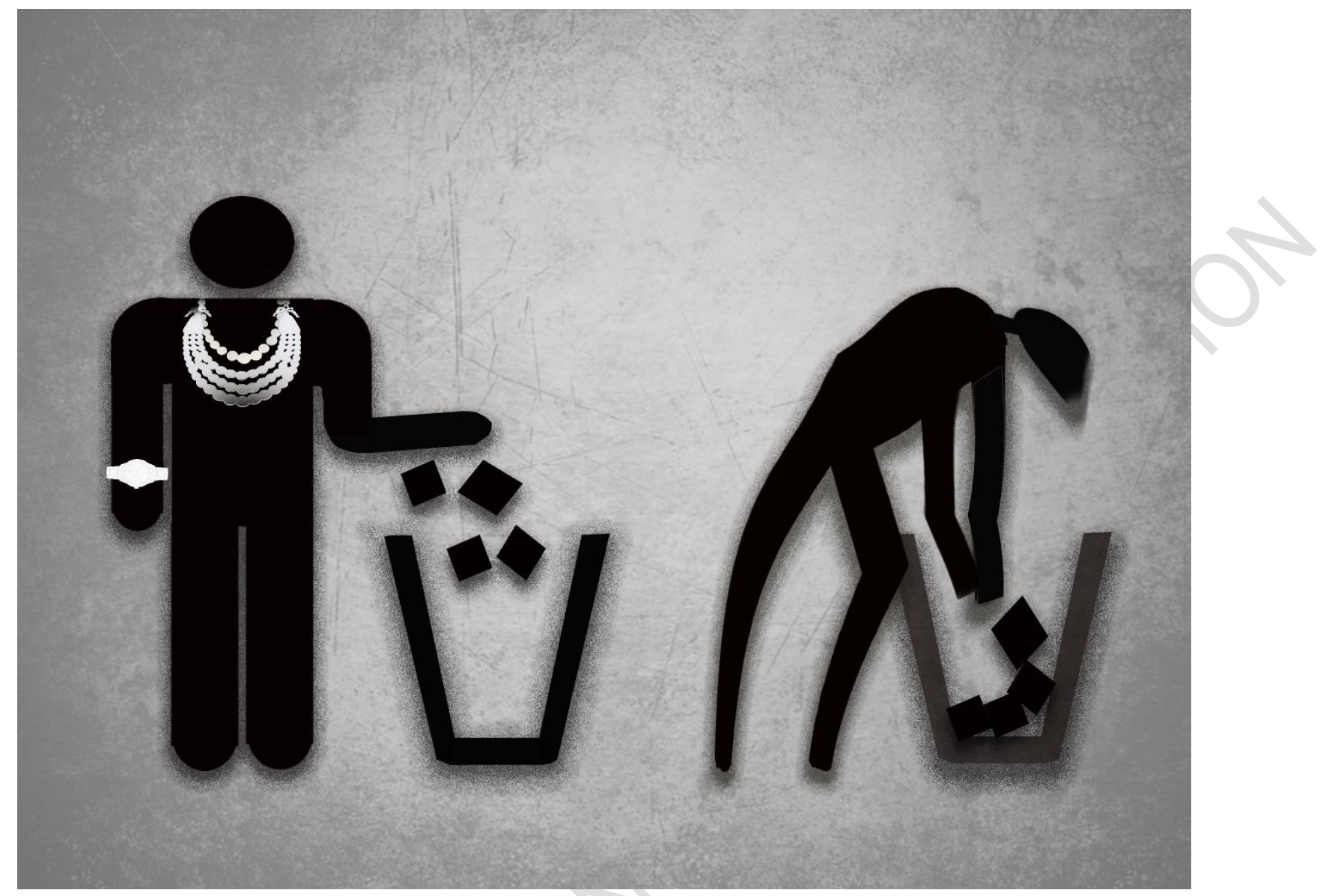

Figure 7. This image has been used to underpin discussion of the relationships between wealth and poverty.

Figure 8. This helped the lecturer to discuss health-related issues, from HIV anti-retroviral in Africa to inequitable distribution of breast cancer treatments in the UK. 


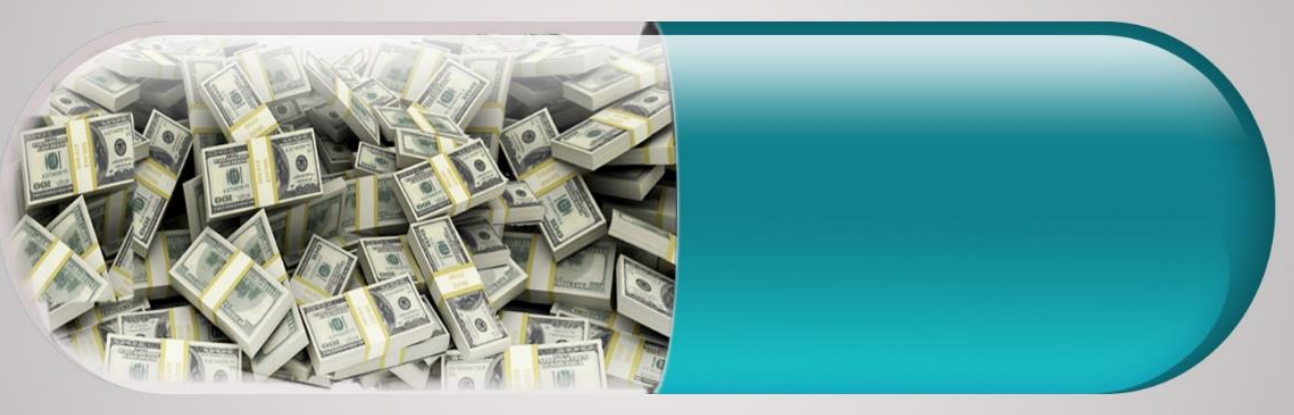

Figure 9. This image supports discussion of a range of topics, from suppression or distribution of antiretroviral drugs in S. Africa to privatization of UK/US/anywhere health sector. 


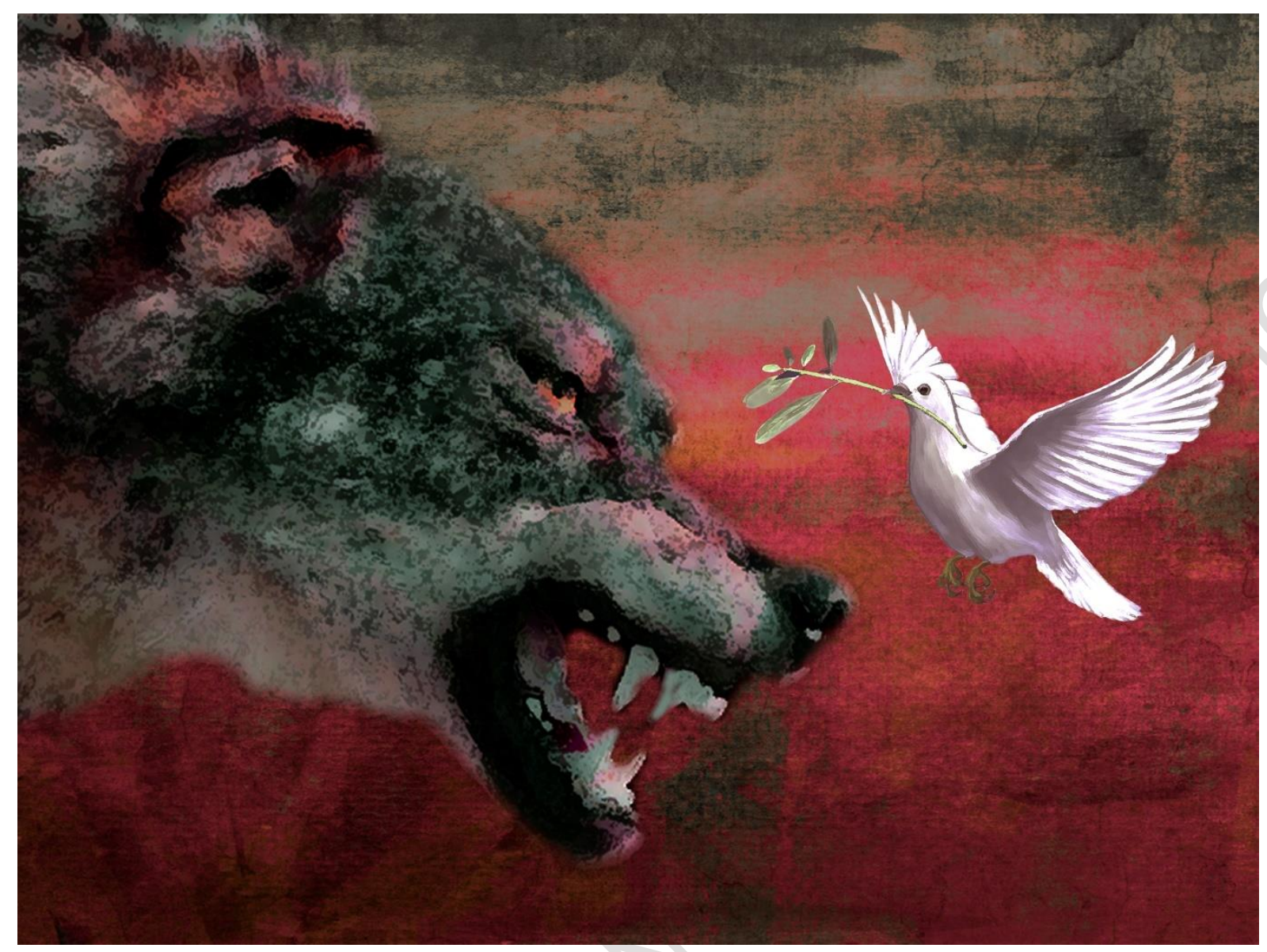

Figure 10. This image portrays the relative hegemony and legitimacy of the use of violence as a means of social transformation.

Group 1 (blue) is the control group tested with standard PowerPoint-style lecture slides, consisting of bullet points and text. Group 2 is the test group exposed to full-slide, highquality images. 


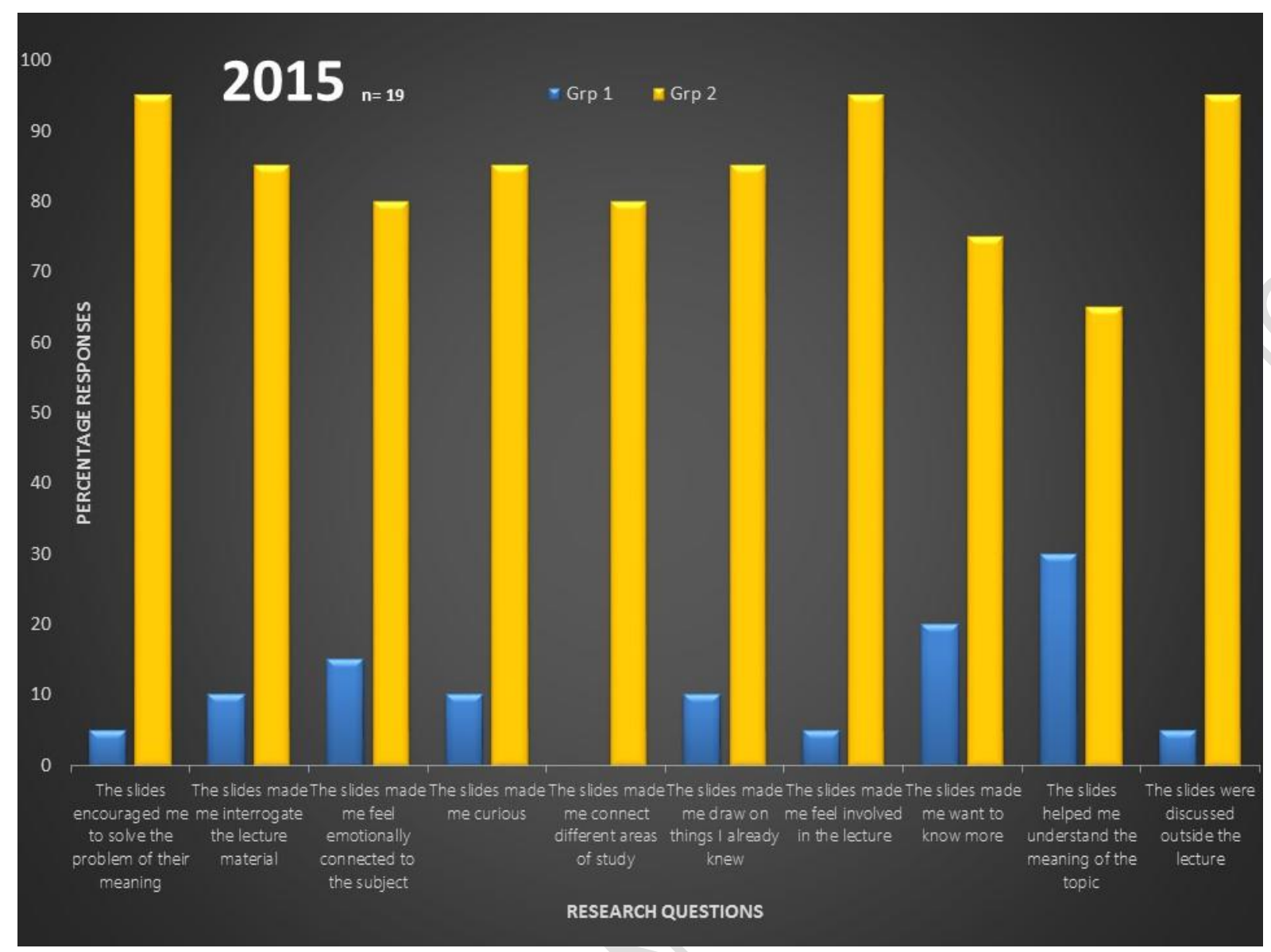

Table 1, 2015

Measures and analysis

After each mini-lecture, each student completed an online survey within 5 minutes of leaving the presentation which asked them to choose on a numbered scale the extent to which they agreed with statements about the value of slides. No reference was made to whether the slides were text-based or visual. Those exposed to text only appear as yellow. Those exposed to images and reduced text appear as blue. The quantitative research established the presence of active learning characteristics.

The qualitative approach was designed to discuss in detail what the processes involved and the ways in which learning was active for students. As with Machemer and Crawford ((2007), the focus group sessions were designed to assess different forms of teaching and were repeated over continuous semesters in both years, with each participant's exposure to the multimedia method having taken place during normal lectures (as opposed to control and test groups). The participants were all under 22, with an average ratio of 30:70 females to males. The discussions lasted an hour and were free-flowing but structured around the characteristics identified by Levy (2012). The same cohort that provided volunteers for the quantitative exercises also provided students after they were emailed by this lecturer. The focus groups were semi-structured, meaning that this discussion leader introduced the key characteristics of active learning identified in the literature and then asked the focus group 
volunteers to elaborate on how they manifested and what they involved. In both years, students from each group completed a survey questionnaire after they had seen a presentation. They did this through the Bristol Online Survey (BOS) system, recognised and used by academic institutions in the UK. The software organised and generated data automatically and these results were then represented in colour graphs.

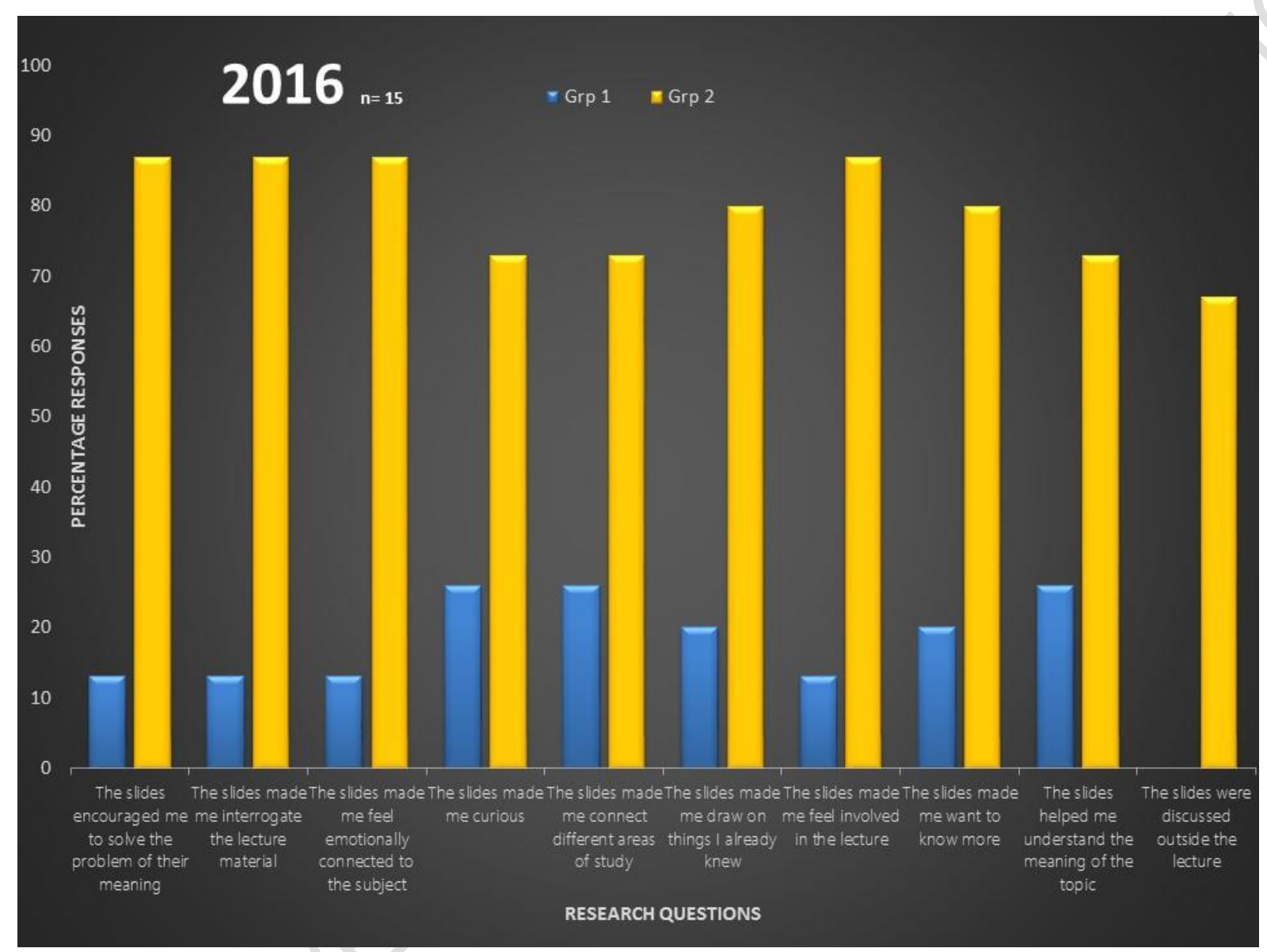

Table 22016

\section{Results}

The graphs reveal a pattern evident in both years. There is a substantial difference between the two groups in terms of the presence of active learning characteristics. They are primarily absent for Group 1 (the control group, tested with standard Powerpoint-style lecture slides, consisting of bullet points and text) and predominant for Group 2 (the test group, exposed to full slide, high quality images and no text).

In line with social evolution beyond the university, one student compared the method with her experiences in art galleries and museums, where visitors are often provided with an audio track played through earphones whilst simultaneously visually absorbing an artefact. After identifying this comparison, she commented that 
when you're looking at a picture you're trying to figure out what the artist intended. It's an interpretive process, just like with images in a lecture. They grab your attention because you want to know what it is you're looking at. You can listen and see without one blocking the other out. But if you're trying to read and listen to someone talking, one blocks the other out.

This prompted others, one of whom said that 'when there's text on the slide, I'm too busy copying it or paraphrasing it to hear what the lecturer is saying about it. One cancels the other out'. He then added that 'I have to make a choice. Am I going to listen to the lecturer, or am I going to read the text he's providing? I can't read the text and listen as well'.

There was broad agreement in the focus groups that using images with text was better than using text alone, reflecting the quantitative findings, but this did not imply that all images were treated similarly. The method deploys three types. First is a literal image. This is the simplest, and manifests a visual representation of a subject. For example, if discussing the $\mathrm{EU}$, we may use an image of the EU flag. Using an image of desertification whilst discussing global warming and its impact on people and animals led one student to declare that she 'had no idea it looked like that. I could understand why it would be seen as a threat to people. It really got my attention because I could see the consequences for the first time. I never thought a picture of sand would impact me so much'. Another referred to an image I used when discussing the war in Vietnam. This was the iconic Pulitzer Prize-winning image by Nick Ut of Kim Phuc, the naked girl burned by napalm and fleeing an ongoing attack. The student said:

You had my attention when you were talking about the Viet Nam war and showed the image of the girl running down the road and the bombs falling behind her. I could understand why people in the south hated the American forces. I understood in that picture why America lost the war.

For one slide to be able to express a complex idea is a noteworthy feat, in the context of multimedia learning claims that images convey meaning. This was a literal image; results for a second category of images known as figurative (metaphor) images had a more frequent and broad impact.

Metaphor images were very popular with students in the focus groups. An example is figure 5. 'The image is indelible. It says everything about the safety problems of nuclear power stations'. Another student said the pulling of a pin to detonate a grenade implied a 'manmade disaster' - not something unavoidable. The image had been interpreted as revealing a constructivist process. In another example, the entire story of evolution is told in one image. Third year students recalled this from their first year. They said that they 'had to map the content, assemble its component parts from what I already knew about evolution'. The story was of a historical process, whereby 'we came from the sea by way of DNA into a 
primitive world that shaped us as people'. The image 'puzzled at first', then there was 'relief' in decoding its meaning. The student continued: 'I didn't even realize what I was doing. I was just in the picture, thinking about it whilst you talked'. This was a common theme across all the focus groups - there was an interactive journey into which students were drawn by their own curiosity as to what the metaphor meant.

Students in the focus groups felt that they had no choice but to engage: the images provoked interrogation because they were 'illogical', 'irrational', 'wrong', 'surprising', 'perplexing' and 'needed to be reconciled'. Students were almost unanimous that paradox images with opposing elements mean 'you are working the problem. I really like the problem-solving - what is going on in the image forces you to work it out because it presents a problem'. In another example, of a pill containing not medicine but skulls, one student described what happened as she looked at it and listened to the lecture.

I see the pill and think health, then I see the skulls and I think that's not right. I see the pill and have thoughts about health; I see skulls and have thoughts of death. Then I try to link it with what the lecturer is saying, and it completes a circle and brings it to life. I can then understand more about the morality of Big Pharma charging poor people for life-saving medicine or something like that. The confusion the image creates makes me try to reconcile the content, which means I am thinking of explanations myself whilst the lecturer is talking around it. I am asking, why is there an image that's created like that? It goes against what I thought I knew, what I'd been told, what I'd learned before.

Most students in each focus group affirmed the presence of such a process. Put simply, students seeing metaphorical and paradoxical images (some may be mixtures of both) 'make linkages and build on them'. One student elaborated with regard to an image referring to the Cold War:

it makes me think: what did I know about the Cold War? How does the image relate to the Cold War? What have I learned now about the Cold War? Why does this image work with the Cold War? I come to my own answers in parallel with the lecturer's comments. I'm half the deal. I'm not just sitting silently on 'receive', I'm working to understand, using my brain to ask questions. It's almost the opposite of a normal lecture.

She went on to add that 
This is a case of image content challeng[ing] our pre-conceived ideas, forc[ing] us to question what we came to the lecture with. It helps you think more critically. With images, you're thinking about them all the time, rather than just reciting learning from the slide. The \{Cold War] image forced me to question what I already knew and draw a different conclusion from it. I was learning for myself instead of being taught to.

Further interrogation of the students led to a deeper elaboration of these processes that affirms the presence of active learning characteristics. A second-year undergraduate remarked thus:

I start not knowing what the image is. Watching a confusing image makes me want to hear what the lecturer has to say about it. I need to work the image out, whereas if it's just text I'm bored. I don't need to work anything out; I just rewrite what I'm being shown on the slides. Being confused like that keeps you stimulated the whole lecture, especially since we know there will be more images like this and more puzzles to understand. It keeps us on our toes.

The final question asked of the focus groups sought a general sense of whether any learning they might be experiencing seemed to them like active learning, and how that compared with text-centric slides. It is summed up well in the following remarks: 'most of my lecturers just put text up. I'm instantly bored by text. I'm instantly drawn to a picture... 'images up the ante and give me autonomy, make me active in the lecture, instead of text that spoonfeeds me'. The view was unanimous in each focus group in each year. One student put it thus: 'if your brain is engaged enough to be asking, "what is that?", then you are definitely active in the learning process. I'm involved in these lectures. I'm busy'.

The findings of the research affirm the capacity of multimedia learning methods specifically, the use of high-quality, full-slide images - to induce key characteristics of active learning in large group lectures. Control/test group quantitative testing revealed active learning characteristics were present in $10 \%$ of a lecture delivered using slides filled with text, but were present in between $60-90 \%$ of the same lecture delivered via slides using images. In qualitative investigation, students explained how interrogative images presented problems that demanded resolution, stimulating their attention and engagement and involving them in much more than duplicating and regurgitating material. The images made them think about their meaning or just familiarized them with the unfamiliar. They also prompted curiosity in intellectual content and an opportunity for them to build on existing knowledge as co-producers of knowledge. 


\section{Discussion and conclusions}

Multimedia learning theory does not predict active learning processes; it is mainly concerned with efficiency and engagement. But research conducted to test those propositions hinted that characteristics of active learning were present because of the use of images. This new research was conducted specifically to develop data on the presence or absence of active learning processes in large group settings that use multimedia methods. The findings presented above indicate a substantial elevation of active learning processes due to the use of high-quality, full-slide illustrative, metaphoric and paradox images. We may now reasonably proceed on the basis that there is value to using multimedia learning visual methods as a means by which to generate active learning behaviours in large group teaching.

This is noteworthy because large group lectures will almost certainly remain a common means by which higher education is delivered, despite the concern that they are primarily passive means by which knowledge is transmitted. This stands in contrast with the idea that students are better served for life when they are encouraged to find ways to solve problems by recognizing value in their existing knowledge and modifying that knowledge in the light of new academic challenges and experiences. In this understanding of the process, the lecturer has a key role to play but not as sole knowledge provider or 'sage on the stage'. As one of the focus group respondents put it, 'it's the lecturer's job to guide the curiosity the images create towards our understanding. That's different from a lecturer telling us what it all is. That approach leaves us out of the process of coming to understand'.

The data also allow us to consider some important qualifications. First, apposite images that convey relevant meaning, even if only descriptive, serve the dual purpose of exploiting visual processing whilst also reducing the harmful effects of excessive text. Second, metaphor and paradox images - readily accessible on line - are more engaging because they are not immediately comprehendible. Paradoxes and metaphors have been identified by these focus groups as playing a role in creating an active, interrogative process guided by a lecturer that prompts intellectual curiosity and engagement and shifts the balance of knowledge production from lecturer-dominant to a co-productive symbiosis.

Perhaps the most obvious limitation pertains to the number of participants, as this was a very small-scale study. A second limit is that all the students came from the same institution, and from the same country/culture, reflecting a narrow demography. Further, they were already familiar with the visual method from lectures they had participated in as part of their regular curricula. Third, it is possible the focus groups captured to some extent students who were already enthused by the method. Fourth, the study only captures data from two years. The limits outlined here are reshaping future research in interesting ways. The focus exposed an ever-increasing demand for students to engage with the university in nonacademic arenas, like volunteering for open day tours, preparation for the National Student 
Survey (a survey carried out in the UK which attempts to measure student satisfaction and related matters) and contribution to regular surveys concerning issues like module and curricula quality assurance. It became clear, however, that probably the biggest reason students were unwilling to participate was that it required them to come onto campus to see the presentations. If the control/test group mini-lectures could be placed online and connected to the survey, there might be a higher uptake after the initial email request for participants. To this end, future work could involve the development of a website that contains both presentations with their narrations. Equitable choice between whether to see the text slides or the image slides may be managed by a mutating URL created by one of the students. This method would be how future data could be captured and it means it could be extended to students at other universities and disciplines, through other Centres for Academic Practice and student group Facebook pages, for example. There is also a need to extend the research to the science subjects, mirroring NASA's new visual arts project to make scientific complexity more comprehendible to wider audiences.

The means to engage and involve students at other institutions is also needed., to take the research to students at universities reflecting different demographics and, indeed, other countries' higher education systems.

There is also a need to look at students with different learning needs, such as those with dyslexia, because of widely-understood problems with text handling and preferences for imagery with such learners.

The higher education mainstay pedagogy of large group lecturing provides a great challenge if passive learning is to be overcome. To date, many lecturers have attempted to interrupt the passive lecture space with active learning pedagogies. This research is instead an experiment in transforming the whole lecture space so it is predominantly active in nature. The study indicates that the under-considered visual learning element of Levy's (2012) conceptualization of active learning merits closer attention, especially since initial indicators suggest applicability in a wide range of university subjects. If no other lessons or message emerge from this research, it is that whilst text-filled slides have their place, that imagery has profound pedagogic value because human beings are 'dual processors' of information. 


\section{References}

Anthony, G., 1996. Active Learning in a Constructivist Framework. Educational Studies in Mathematics, 31(4), 349-369.

Ayres, P., 2015. State-of-the-Art Research into Multimedia Learning: A Commentary on Mayer's Handbook of Multimedia Learning. Applied Cognitive Psychology, 29(4), 631-636. Baeten, M., Kyndt, E., Struyven, K. and Dochy, F. (2010). Using student-centred learning environments to stimulate deep approaches to learning: Factors encouraging or discouraging their effectiveness. Educational Research Review, 5(3), 243-260.

Bailey, A and Ngwenyama, O. (2010) Bridging the Generation Gap in ICT Use: Interrogating Identity, Technology and Interactions in Community Telecenters, Information Technology for Development, 16, 62-82

Baxi, U., 1998. Voices of Suffering and the Future of Human Rights. Transnational Law and Contemporary problems, 125(8), 125-170.

Beacham, N. \& Alty, J., 2006. An investigation into the effects that digital have on the learning outcomes of individuals who have dyslexia. Computers and Education, 47(1), 7493.

Bergman, R., 2012. Five Steps to Conquer 'Death by PowerPoint'. London: CreateSpace Independent Publishing Platform.

Bradfield, R., Cairns , G. \& Wright, G., 2015. Teaching scenario analysis—An action learning pedagogy. Technological Forecasting and Social Change, 100(3), 44-52.

Brumberger, E., 2011. Visual Literacy and the Digital Native: An Examination of the Millennial Learner. Journal of Visual Literacy, 30(1), 19-47.

Bumiller, E., 2010. We have met the enemy and he is PowerPoint, New York: New York Times. Chanlin, L., 1998. Animation to teach students of differing knwledge levels. Journal of Instructional Psychology, 25(3), 166-175.

Clark, R. \& Lyons, C., 2010. Graphics for Learning: Proven Guidelines for Planning, Designing, and Evaluating Visuals in Training Materials. Oxford: Wiley.

Coates, J., 2006. Generational learning styles. River Falls, Wisconsin: LERN.

Cuthbertson, R., Furseth, P. I. \& Ezell, S. J., 2015. Innovating in a Service-Driven Economy: insights, application and practice. London: Palgrave Macmillan.

Dent-Read, C., Klein , G. \& Eggleston R. , G., 1994. Metaphor in visual displays designed to guide action. Metaphor and Symbolic Activity, 9(3), 211-232.

Donald, M., 2014. CADMUS. [Online] Available at: http://cadmusjournal.org/node/400

[Accessed 2 July 2015].

Edelson, D., Gordin , D. N. \& Pea, R. D., 1999. Addressing the Challenges of Inquiry-Based Learning Through Technology and Curriculum Design. The Journal of the Learning Sciences, 8(3-4), 391-450.

Eliason, JL (1996). Using paradoxes to teach critical thinking in science. Journal of College Science Teaching 25(5), 341-344: 341Ellis R A. (2016) Qualitatively different university student experiences of inquiry - associations amongst approaches to inquiry, technologies 
and perceptions of the learning environment. Active Learning in Higher Education 17(1): 1323.

Eppler, M., 2006. A comparison between concept maps, mind maps, conceptual diagrams, and visual metaphors as complementary tools for knowledge construction and sharing. Information Visualization, 5(3), 202-210.

Felten, P., 2008. Visual Literacy. Change: The Magazine of Higher Learning, 40(6), 60-64.

Gabriel, Y., 2008. Against the Tyranny of PowerPoint: Technology-in-Use and Technology Abuse. Organisation Studies, 29(2), 255-276.

Gaskins, R., 2012. Sweating Bullets: Notes about Inventing PowerPoint. New York: Vinland Books.

Goldfarb, B., 2002. Visual Pedagogy: Media Cultures in and beyond the Classroom. Durham (US): Duke University Press.

Guertin, L.A. (2010) 'Creating and Using Podcasts Across the Disciplines', Currents in Teaching and Learning 2(2): 4-12

Hargittai, E. (2010) Digital Na(t)ives? Variation in Internet Skills and Uses among Members of the "Net Generation", Sociological Inquiry, 80, 1, 92-113

Hmelo-Silver CE (2004) Problem-Based Learning: What and How Do Students Learn? Educational Psychology Review 16(3): 235-266.

Hockley, W. \& Bancroft, T., 2011. Extensions of the picture superiority effect in associative recognition. Canadian Journal of Experimental Psychology, 65(4), 236-244.

King, F., 2016. Visual approaches to property law pedagogy. International Journal of Law in the Built Environment, 8(1), 80-94.

Kleinman, E. \& Dwyer, F. M., 1999. Analysis of computerized visual skills: relationships to intellectual skills and achievement. International Journal of Instructional Media, 26(1), 53-69. Kosslyn, S., 2007. Clear and to the Point : 8 Psychological Principles for Compelling. New York: Oxford University Press.

Laurillard, D. (2013). Rethinking university teaching: A conversational framework for the effective use of learning technologies. Routledge

Lawson, S., Sanders, K., \& Smith, L., 2015. Commodification of the Information Profession: A Critique of Higher Education Under Neoliberalism. Journal of Librarianship and Scholarly Communication, 3(1), 1-24.

Levy, P., 2012. Developing inquiry-guided learning in a research university in the United Kingdom. In: Inquiry as a Way of Learning in Undergraduate Education. New Directions for Teaching and Learning. San Francisco, CA: Jossey Bass, 15-26.

Lewis, P., 2016. Brain Friendly Teaching-Reducing Learner's Cognitive Load. Academic Radiology, 23(7), 877-880.

Machemer PL and Crawford P (2007) Student perceptions of active learning in a large-cross disciplinary classroom, Active Learning in Higher Education

Mathis, G., 2015. Inquiry-Based Learning: The Power of Asking the Right Questions. [Online] Available at: http://www.edutopia.org/blog/inquiry-based-learning-asking-rightquestions-georgia-mathis [Accessed 10 June 2016].

Mayer, R., 2014. The Cambridge Handbook of Multimedia Learning. 2nd ed. New York: Cambridge University Press. 
Mayer, R. \& Moreno, M., 2003. Nine Ways to Reduce Cognitive Load in Multimedia Learning. Educational Psychologist, 38(1), 43-52.

McKay, E., 1999. An investigation of text-based instructional materials enhanced with graphics. Educational Psychology, 19(3), 323-335.

McStay, A., 2013. Creativity and Advertising: Affect, Events and Process. London: Routledge. Michael, J., 2006. Where's the evidence that active learning works?. Advances in Physiology Education, 30(4), 159-167.

Mitchell, W., 2002. Showing seeing: a critique of visual culture. Journal of Visual Culture, 1(2), 165-181.

Morris C and Chikwa G. (2014) Screencasts: how effective are they and how do students engage with them? Active Learning in Higher Education 15, 1, 25-37.

Moss, J. \& Pini, B., 2016. Visual Research Methods in Educational Research. London:

Palgrave Macmillan.

Paivio, A., 1971. Imagery and verbal processes. New York: Holt, Rinehart, and Winston.

Paivio, A (2014). Mind and its evolution. A dual-coding theoretical approach. Oxford:

Psychology Press

Palfrey, J. and Gasser, U. (2008) Born Digital: Understanding the First Generation of Digital Natives, Basic Books, NY

Prensky, M., 2001. Digital natives, digital immigrants. On the Horizon, 9(5), pp. 1-6.Prince, M., 2004. Does Active Learning Work? A Review of the Research. Journal of Engineering Education, 93(3), 223-231.

Prosser M and Trigwell K. (2014) Qualitative variation in approaches to university teaching and learning in large first-year classes. Higher Education 67, 6, 783-795Savery, J., 2006. Overview of Problem-based Learning: Definitions and Distinctions. The Interdisciplinary Journal of Problem-based Learning, 1(1), 9-20.

Schrand, T., 2008. Tapping into active learning and multiple intelligences with interactive multimedia: a low-threshold classroom approach. College Teaching, 56(2), 78-84.

Siegel, L. \& Ryan, E. B., 1989. The Development of Working Memory in Normally Achieving and Subtypes of Learning Disabled Children. Child Development, 60(4), 973980.

Smith C M and Sodano T M. (2011) Integrating lecture capture as a teaching strategy to improve student presentation skills through self-assessment. . Active Learning in Higher Education 12, 3, 151-162

Stes A., de Maeyer S., Gijbels D. and van Petegem P. (2012) Instructional development for teachers in higher education: effects on students' perceptions of the teaching-learning environment. British Journal of Educational Psychology 82(3): 420-435 Torp, L. \& Sage, S., 2002. Problems as possibilities: Problem-based learning for K-16 education. Alexandria, VA: Association for Supervision and Curriculum Development. von Stumm, S. and Furnham, A. F. (2012). Learning approaches: Associations with typical 
intellectual engagement, intelligence and the big five. Personality and Individual Differences, 53(5), 720-723

Williams, V., 1998. Creating Effective Visual Metaphors. [Online] Available at:

http://www.google.co.uk/url?sa $=t \& r c t=j \& q=\& e s r c=s \&$ source $=$ web \& $c d=5 \& v e d=0 C D U Q F j$ AE\&url=http\%3A\%2F\%2Fwww.personal.psu.edu\%2Fstaff\%2Fv\%2Fq\%2Fvqw\%2FPortfolio \%2FVislMeta.pdf\&ei=FxZiVe7IC8GsU9vhgfgG\&usg=AFOjCNFfV8D7xsu5KYjhTjsDKwkVHRY -Ow\&sig2=tq|THO|MMa anqDOfX5Lf [Accessed 24 May 2015].

Winterbottom, M., 2016. Active Learning. [Online] Available at:

www.cie.org.uk/images/271174-active-learning.pdf [Accessed 10 June 2016].

Zepke N. (2013) Threshold concepts and student engagement: Revisiting pedagogical content knowledge. Active Learning in Higher Education 14 (2): 97-107.

Zepke $N$ and Leach L (2010) Improving student engagement: Ten proposals for action. Active Learning in Higher Education 11 (3): 167-177. 